\title{
People Behind the Long-Acting Injectable Antipsychotics: Do We Really Know Them?
}

19.1 WPA WORLD

\section{J. Borba Martins*, M. Corvacho*, M. L. Costa*, S. Batista*, A. C. Trindade*}

"Centro Hospitalar Universitário do Algarve, Department of Psychiatry and Mental Health, Faro, Portugal

\section{OBJECTIVES}

Long-acting injectable (LAl) antipsychotics remain among the most effective treatments in Psychiatry ${ }^{1}$. This study assessed and compared clinical and sociodemographic characteristics of patients of a Community Mental Health Team (CMHT), focusing on those under LAl treatment.

\section{BACKGROUND AND AIMS}

Studies indicate that nearly $60 \%$ of people diagnosed with mental illness have not received any mental health services in the prior year and, of the remaining $40 \%$, two-thirds do not remain adherent to medication in the year following diagnosis ${ }^{2}$. Although LAI have potential disavantadges such as longer time to achieve steady state levels, delayed disappearance of side effects and the perception of stigma, their potential advantages are of greatest importance: e.g. reduced peak-trough plasma levels, early identification of non-adherence, regular interactions between patients and $\mathrm{CMHT}$ staff and reduced relapse frequency and rehospitalization rates ${ }^{3}$.

This study intends to compare clinical and sociodemographic variables in order to contribute to the optimization of our practice.

\section{MATERIALS AND METHODS}

The data sample was obtained from the adult ambulatory services of the CMHT of Olhão and S. Brás de Alportel, Algarve, in February 2019.

\section{RESULTS}

$22 \%$ of our sample $(\mathrm{N}=696)$ is being treated with $\mathrm{LAl}, 16 \%$ of them under compulsory treatment (Law Nr. 36/98, of July 24th - Mental Health Portuguese Law). Among those treated with LAI, $69 \%$ are male, against $36 \%$ on the non-LAI group (Graph 1). Concerning age distribution, non-LAI and LAI patients present the same trend. $85 \%$ of those treated with LAI suffer from a psychotic disorder and, as expected, the majority of patients with psychotic disorders (57\%) are under LAI (Graph 2): Haloperidol (32,8\%), Paliperidone (23,4\%), Flupenthixol (16,4\%), Zuclopenthixol (16,4\%), Risperidone (10,2\%), Aripiprazole (0,8\%) .
Graph 1 - Gender per LAI/Non-LAl Patients

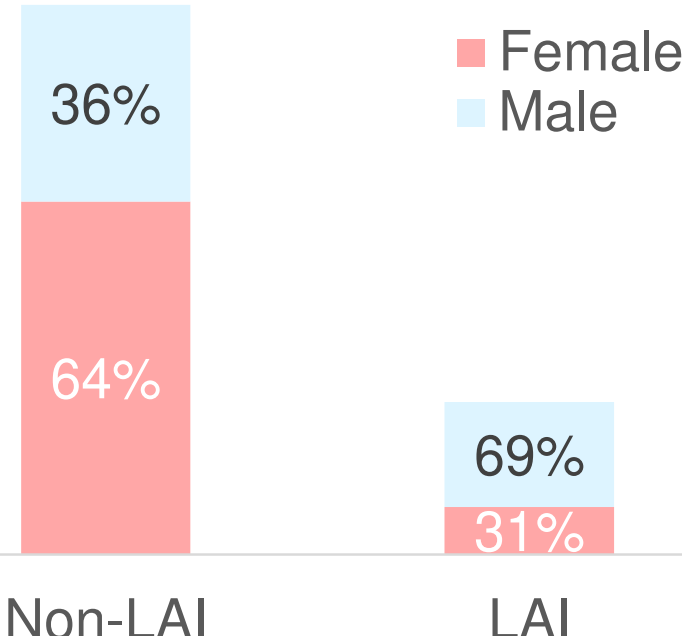

Graph 2 - LAI/Non-LAl according to disease groups

Cluster A Personality Disorder

Obsessive-Compulsive Disorder

Anxiety/Depressive Disorders

Cluster B Personality Disorder

Dementia

Cluster C Personality Disorder

Bipolar Disorder

Psychotic Disorders
$100 \%$

Non-LAI

\begin{tabular}{|c|c|c|}
\hline Dementia & $90 \%$ & $10 \%$ \\
\hline Cluster C Personality Disorder & $89 \%$ & $11 \%$ \\
\hline Bipolar Disorder & $85 \%$ & $15 \%$ \\
\hline Psychotic Disorders & $43 \%$ & \\
\hline
\end{tabular}

\section{CONCLUSIONS}

Despite identified advantages, LAI are not used as widely as it might be expected; although the majority of patients with psychotic disorders (57\%) are under treatment with LAI antipsychotics, we could expect a percentage higher than $57 \%$. It is also noticeable that first-generation antipsychotics account for $65,6 \%$ of the prescribed LAI, what is probably explained by the population low income level, regarding that in our country LAI antipsychotics are not $100 \%$ supported by the National Health Service; this would be an important political resolution not only to improve patients' quality of life, but also to reduce the socioeconomical burden of clinical relapses and hospital admissions. Knowing better the sociodemographic features of our populations is undoubtedly a key factor in promoting their adherence to the treatment - further studies will be useful to quantify it. Despite this, psychiatrists can always play a role in medication adherence by offering LAI antipsychotics when appropriate.

References: 1. Correll et al.; The Use of Long-Acting Injectable Antipsychotics in Schizophrenia: Evaluating the Evidence. The Journal of Clinical Psychiatry 2016, 77 (supplement 3) 2. Maestri et al.; Do Long-Acting Injectable Antipsychotics Prevent or Delay Hospital Readmission? Psychopharmacology Bulletin 2018, 48(3): 8-15; 3. Brissos et al.; The Role of 